\title{
Processing the Bouguer anomaly map of Biga and the surrounding area by the cellular neural network: application to the southwestern Marmara region
}

\author{
Davut Aydogan \\ Istanbul University, Engineering Faculty, Department of Geophysics, 34310, Avcilar, Istanbul, Turkey \\ (Received May 25, 2006; Revised December 22, 2006; Accepted December 25, 2006; Online published May 7, 2007)
}

\begin{abstract}
An image processing technique called the cellular neural network (CNN) approach is used in this study to locate geological features giving rise to gravity anomalies such as faults or the boundary of two geologic zones. CNN is a stochastic image processing technique based on template optimization using the neighborhood relationships of cells. These cells can be characterized by a functional block diagram that is typical of neural network theory. The functionality of CNN is described in its entirety by a number of small matrices $(A, B$ and $I)$ called the cloning template. CNN can also be considered to be a nonlinear convolution of these matrices. This template describes the strength of the nearest neighbor interconnections in the network. The recurrent perceptron learning algorithm (RPLA) is used in optimization of cloning template. The CNN and standard Canny algorithms were first tested on two sets of synthetic gravity data with the aim of checking the reliability of the proposed approach. The CNN method was compared with classical derivative techniques by applying the cross-correlation method (CC) to the same anomaly map as this latter approach can detect some features that are difficult to identify on the Bouguer anomaly maps. This approach was then applied to the Bouguer anomaly map of Biga and its surrounding area, in Turkey. Structural features in the area between Bandirma, Biga, Yenice and Gonen in the southwest Marmara region are investigated by applying the $\mathrm{CNN}$ and $\mathrm{CC}$ to the Bouguer anomaly map. Faults identified by these algorithms are generally in accordance with previously mapped surface faults. These examples show that the geologic boundaries can be detected from Bouguer anomaly maps using the cloning template approach. A visual evaluation of the outputs of the CNN and CC approaches is carried out, and the results are compared with each other. This approach provides quantitative solutions based on just a few assumptions, which makes the method more powerful than the classical methods.
\end{abstract}

Key words: CNN, derivative method, cross-correlation, Canny algorithm, cloning template, gravity anomaly, geological features, southwestern Marmara region, Turkey.

\section{Introduction}

One of the most common problems encountered in geophysical studies is how to determine the subsurface geological features, namely faults or the boundary of two geologic zones at various depths, as it difficult to establish the geological boundaries hidden beneath surface materials. Gravity is an effective geophysical method by which to identify these, and numerous techniques exist in the field of geophysics for analyzing gravity anomalies produced by faults or the boundary of two geologic zones. In this context, boundary analyses of gravity or magnetic anomalies are carried out using various combinations of directional derivative (gradient) techniques. Edge detection algorithms are used for analyzing potential sets of field data, such as gravity and magnetic maps, in order to detect main geological bodies, subtle geological features, geological structures and alignments (Boschetti, 2005). Since the early 1970s, a variety of automatic or semiautomatic methods, all of which are based on the use of the horizontal or vertical gradient of potential field anomalies, have been developed as efficient tools for

Copyright (C) The Society of Geomagnetism and Earth, Planetary and Space Sciences (SGEPSS); The Seismological Society of Japan; The Volcanological Society of Japan; The Geodetic Society of Japan; The Japanese Society for Planetary Sciences; TERRAPUB. the determination of geometric parameters, such as locations of boundaries and the depths of the causative sources. Since potential field data correspond to the superposition of effects from all causative sources, the determination of geologic boundaries usually suffers from nearby source interference that produces false edges. Most of the images need to be enhanced before an edge detection scheme can be applied successfully. Image enhancement is a general term describing the process of manipulating the data in an image to emphasize the features of interest. Of the many methods that exist to evaluate edge detectors, the Canny algorithms (1986) were the first to provide analytic expressions for the criteria that have to be optimized in edge detection.

Geologists and geophysicists are interested in linear anomalies in gravity and magnetic maps that may correspond to subsurface faults, a boundary of two geologic zones and other structural features. The Radon transform is a useful method for analyzing lineaments in a twodimensional (2-D) map, and Sykes and Das (2000) have used this approach transform to enhance linear features in geophysical maps. Boschetti (2005) proposed a number of edge detection algorithms based on gravity gradient. In addition, several edge detection algorithms can be found in earlier publications, all of which are based on image gradi- 
ents. These gradients are calculated from the image itself, rather than from measured data. Thompson (1982) and Reid et al. (1990) have used Euler-based approaches for the detection of borders and estimation of depth from gravity and magnetic anomalies. Fedi and Florio (2001) proposed a new technique called Enhanced Horizontal Derivative (EHD), which they used to analyze gravity and magnetic anomalies. In this technique, various orders of horizontal derivatives are summed, and the vertical derivative is then taken; the location of maxima is used to outline the source boundaries. Zeng et al. (1994) proposed a technique which is based on cross-correlation (CC) between the theoretical anomaly due to a vertical step and the second vertical derivative of the Bouguer anomaly to locate minor faults that may be difficult to identify based only on the Bouguer anomaly map. In this approach, faults are located from the closed maxima or minima on the CC map. Blakely and Simpson (1986) improved the boundary analysis technique, which detects buried geological structures based on the horizontal derivative of gravity data.

The cellular neural network (CNN) approach can also be used for edge detection, data enhancement and the separation of potential field maps. The most popular application of CNN has been image processing, essentially because of its analog feature and sparse connections, all of which are conductive to real time processing. The dynamics of the $\mathrm{CNN}$ approach are described by a system of nonlinear ordinary differential equations and by an associated computation energy function that is minimized during the computation process. A two-dimensional $\mathrm{CNN}$ can be considered to be a two-dimensional filter and has been applied for noise removal, shape extraction and edge detection. In the present study, CNN is used in the edge detection of geological structures. We show that this approach is a useful tool for detecting deep faults, even in presence of shallower near surface features.

Aydogan et al. (2005) recently introduced the CNN algorithm, providing implicitly the expressions necessary to apply the method to the analysis of gravity data. For those interested readers who are not familiar with neural network data analysis techniques, this article is barely comprehensible. In this article, I therefore explicitly provide the details of this method so that any reader will be able to follow the method easily and use it for routine applications. In addition to the numerical examples provided by Aydogan et al. (2005), I also introduce more complex numerical models to illustrate the power of the CNN algorithm. One of the major outcomes of this paper is its contribution to the seismotectonics of the southwestern Marmara sea region where we identify a hidden fault that is not present at the active fault maps of Turkey.

\section{Cellular Neural Network Approach}

The CNN model was introduced by Chua and Yang (1988a, b) and consists of a recurrent nonlinear network in which neurons are locally connected and the dynamics are identical for each node. These neurons are commonly called cells. The connection with the cells outside the $r$ neighborhood is enabled by the propagation effects of the network dynamics. The dynamics of a CNN is described by a set of differential equations. A variety of CNN models have been reported in the aftermath of the introduction of the Chua and Yang network. These models differ in terms of cell complexity, cell parameterization, call dynamics and network topology.

Each cell in a CNN has an input, an internal state and an output. Any one cell is connected only to its neighboring cells. The cell located in the position $(i, j)$ of a two-dimensional $M \times N$ array is denoted as $C_{i j}$, and its $r$-neighborhood $N_{i j}^{r}$ is defined by

$$
\begin{gathered}
N_{i j}^{r}=\left\{C_{k l} \mid \max (|k-i|,|l-j|) \leq r,\right. \\
1 \leq k \leq M ; 1 \leq l \leq N\},
\end{gathered}
$$

where the size of the neighborhood $r$ is a positive integer number.

The state equation for cell $C_{i j}$ is defined as follows:

$$
\begin{aligned}
\frac{\partial x_{i j}(t)}{\partial t}= & -x_{i j}(t)+\sum_{k l \in N^{r}} A_{i j, k l} y_{k l}(t) \\
& +\sum_{k l \in N^{r}} B_{i j, k l} u_{k l}(t)+I_{i j}
\end{aligned}
$$

where $x_{i j}, u_{i j}, y_{i j}$ and $I_{i j}$ are the state, input and output and bias of cell $C_{i j}$, respectively. The state and output vary in time, while the input is static (time independent). Matrices $A_{i j, k l}$, which are the feedback template coefficients (derivative coefficients), and $B_{i j, k l}$, which are the control template coefficients, are connected from cell $C_{k l}$ to $C_{i j}$. The matrices $A(\cdot), B(\cdot)$ and $I$ are known collectively as the cloning template. The feedback control template represents the coupling coefficients of the cells, and this completely defines the behavior of the network with a given input and initial condition.

The output equation is described by the following piecewise linear equation:

$$
y_{i j}(t)=f\left(x_{i j}(t)\right)=.5\left(\left|x_{i j}(t)+1\right|-\left|x_{i j}(t)-1\right|\right),
$$

where $f$ can be any convenient non-linear function, such as the signum, sigmoid or step function.

A significant feature of $\mathrm{CNN}$ is that it has two independent input capabilities: the generic input and the initial state of the cells. These are normally bounded by

$$
\left|u_{i j}(t)\right| \leq 1 \quad \text { and } \quad\left|x_{i j}(0)\right| \leq 1
$$

Similarly, if $|f()| \leq$.1 then $\left|y_{i j}(t)\right| \leq 1$.

As can be seen, the input is represented by the intensity values of the pixels that are stored in the matrix $u$, while the initial state values are stored in the matrix $x$.

The functionality of the CNN array can be controlled by the cloning template $(A, B$ and $I)$, where $A$ and $B$ are $(2 r+1) \times(2 r+1)$ real matrices and $I$ is a scalar number in two-dimensional CNNs. In many applications, A and B are space-invariant.

At a discrete time $k$, the discrete time-cellular neural network (DT-CNN) is a clocked system whose dynamical behavior is described by a set of discrete state equations. In this situation, a cell is defined by its position in the grid and is denoted by the corresponding coordinate $c=\left(c_{x}, c_{y}\right)$, 

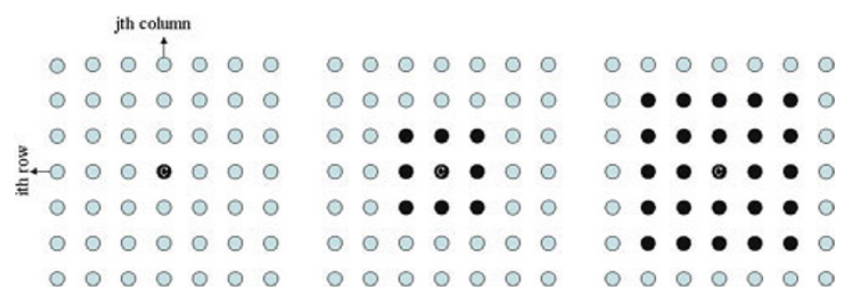

Fig. 1. A two-dimensional CNN defined on a squared grid, a) The $i j$-th cell of the array is colored by black, b) The neighborhood function $N^{r}(c)$ for $\left.r=1, \mathrm{c}\right) r=2$ (neighbor cells are black).

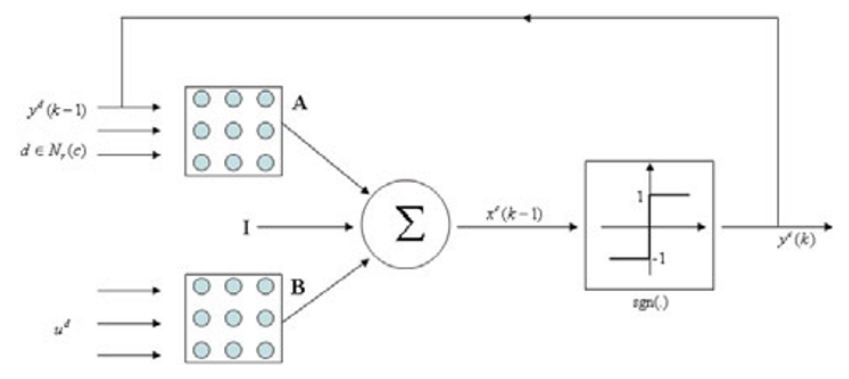

Fig. 2. Block scheme of the DT-CNN cell. $x_{i j}, u_{i j}, y_{i j}$ and $I_{i j}$ are the state, input and output and bias of cell $C_{i j}$, respectively.

where $c_{x}$ denotes the row and $c_{y}$ denotes the column. Each cell connects directly with the set of cells that are within a certain distance $r$ of $c$. This set is the $r$-neighborhood that is defined for $r \geq 0$ by:

$$
N^{r}(c)=\left\{d \in Z^{2} \mid \max \left(\left|d_{y}-c_{y}\right|,\left|d_{x}-c_{x}\right|\right) \leq r\right\} .
$$

For $r=1$ and $r=2$, the $r$-neighborhood is shown in Fig. 1. At the discrete time $k$, the state $x^{c}$ of a cell $c$ depends on the time-independent input $u^{d}$ applied to its neighboring cells $d$ and the time-variant outputs $y^{d}(k)$. The cell state equation is given by:

$$
x^{c}(k)=\sum_{d \in N^{r}(c)} A y^{d}(k)+\sum_{d \in N^{r}(c)} B u^{d}+I .
$$

Consequently, the output of cell $c$ at time step $k>0$ is obtained by threshold state of $c$ at time $k-1$ :

$$
\begin{aligned}
y^{c}(k) & =\operatorname{sgn}\left(x^{c}(k-1)\right) \\
& =\left\{\begin{array}{lll}
+1 & \text { for } \quad x^{c}(k-1) \geq 0 \\
\hline-1 & \text { for } \quad x^{c}(k-1) \prec 0
\end{array}\right.
\end{aligned}
$$

In the case of non-zero feedback coefficients, the output for $k=0$ needs to be specified. As in differential equations where the solution depends on the initial conditions, the initial output $y^{c}(0)$ is of crucial importance to the behavior of the system. In the case when all feedback coefficients are zero, the initial output does not influence the final output of the system. The output of the system remains constant after the first time step. The block diagram of a DT-CNN is demonstrated in Fig. 2.

\section{Template Design for the CNN}

The design of templates $A, B$ and $I$ are necessary if the $\mathrm{CNN}$ approach is to be used for gray scale image processing. A learning procedure can be applied to estimate these

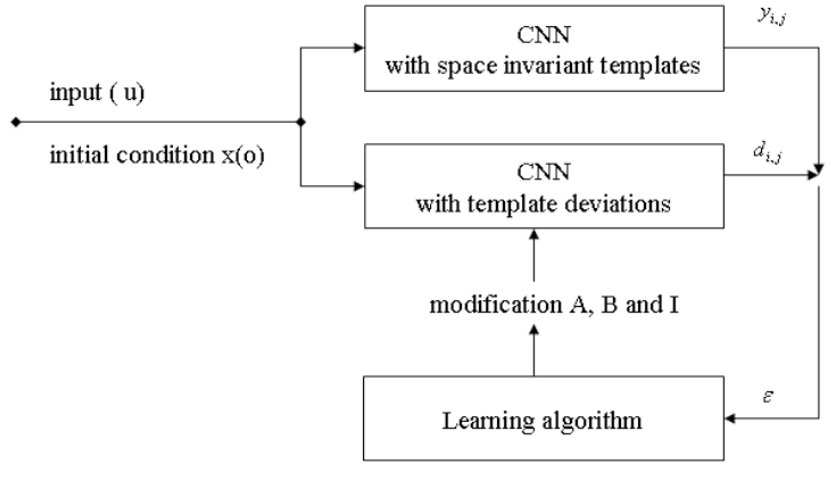

Fig. 3. Learning algorithm scheme.

templates, which determine the desired CNN behavior. All global learning methods are based on minimizing an error function $(\varepsilon)$ - that is a function defined in terms of the desired network output and the actual network output. In this study, the recurrent perceptron learning algorithm (RPLA) is used. The form of the template is as follows:

$$
A=\left[\begin{array}{lll}
a_{2} & a_{1} & a_{2} \\
a_{1} & a_{0} & a_{1} \\
a_{2} & a_{1} & a_{2}
\end{array}\right], \quad B=\left[\begin{array}{lll}
b_{2} & b_{1} & b_{2} \\
b_{1} & b_{0} & b_{1} \\
b_{2} & b_{1} & b_{2}
\end{array}\right], \quad I .
$$

For stability template $A, B$ should be symmetrical and $a_{0}$ must be greater than zero for edge detection. This template, $w$, can be defined as a vector:

$$
w=\left[\begin{array}{lllllll}
a_{0} & a_{1} & a_{2} & b_{0} & b_{1} & b_{2} & I
\end{array}\right]
$$

where $a_{i}$ denotes the feedback coefficients, $b_{i}$ denotes the control coefficients and $I$ is the cell bias or threshold.

The error function of all cells is shown as:

$$
\varepsilon[w]=\sum_{c} \sum_{i, j}\left(y_{i, j}^{c}-d_{i, j}^{c}\right)^{2},
$$

where $y$ is the actual output and $d$ is the desired output. A learning procedure scheme is shown in Fig. 3. A 2-D CNN can be viewed as a 2-D filter and can be applied for noise removal, shape extraction and edge detection.

\section{Application to Synthetic Data}

\subsection{Multiple sources (model 1)}

In this section, synthetic models are used to check the reliability of the proposed approach. Some practical results are presented and briefly discussed to demonstrate the success of the proposed algorithm. The synthetic gravity anomaly map shown in Fig. 4(b) was produced by using finite rectangular vertical prisms located at various depths. The prisms B and C are deeper than the prisms A and D (Fig. 4(a)). In the present study, it is assumed that 1 pixel corresponds to $1 \mathrm{~km}$. The model is $101 \times 101$ pixels wide.

In this example, we wish to locate the edges of the prisms from Bouguer anomaly using the CNN method. The results of the CNN method (Fig. 4(c)) and of the CC method (Figs. 4(d), (e)) were compared. CNN is an adaptive stochastic method in which the filtering properties can be altered according to the input-output matrices. In CNN, the optimization of $A, B$ and $I$ (cloning template) is sufficient in itself to obtain the desired filter properties. RPLA 

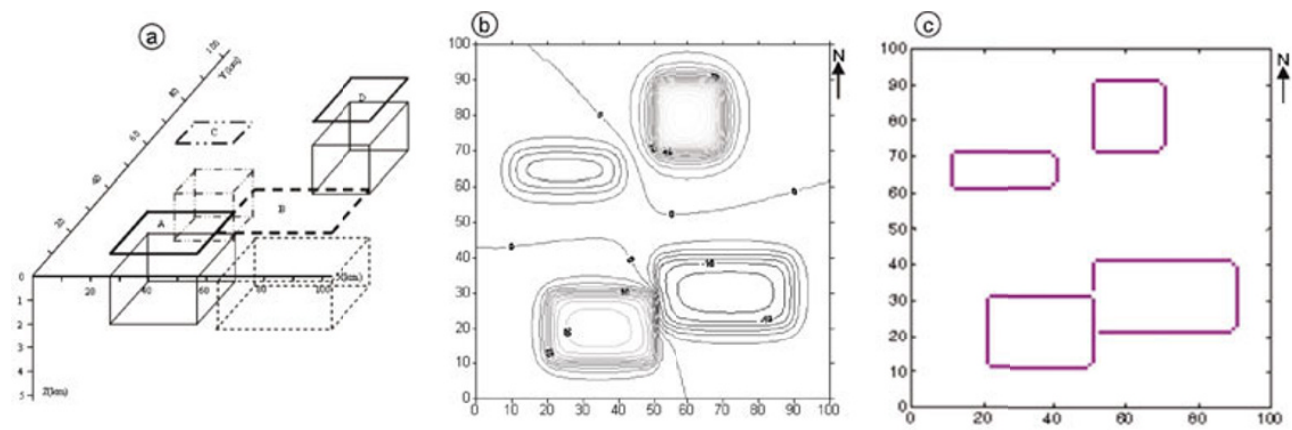

(d)
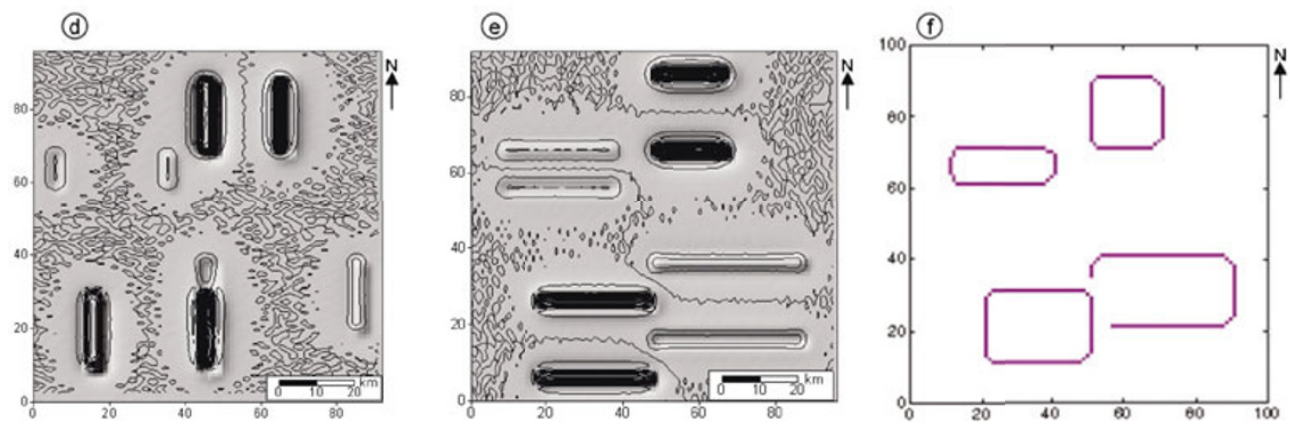

Fig. 4. Synthetic example: (a) Schematic outlines of model 1, (b) synthetic anomaly map (contour interval is 2 mGal), (c) edge map from CNN, (d) gray-shaded relief of cross-correlation map in the E-W direction, (e) gray-shaded relief of cross-correlation map in the N-S direction, (f) edge map obtained by standard Canny algorithm. Cross-correlation maps are illuminated from the NW.

is used to optimize the cloning template. For $r=1$, this optimal template is determined to be:

$$
\begin{aligned}
A & =\left[\begin{array}{lll}
0 & 0 & 0 \\
0 & 2 & 0 \\
0 & 0 & 0
\end{array}\right], \\
B & =\left[\begin{array}{ccc}
-.51 & -.51 & -.51 \\
-.51 & 5.8 & -.51 \\
-.51 & -.51 & -.51
\end{array}\right], \quad I=-2.6 .
\end{aligned}
$$

During the learning procedure, in feedback matrix, only the $a_{0}$ coefficient is found to be greater than zero, while in the control matrix, all coefficients are -0.51 , except for $b_{0}$, which is 5.8. In this case, the control coefficients $\left(b_{i}\right)$ are qualitatively the same as the coefficients of the derivative method. Finally, the bias value $I$ is estimated to be -2.6 . This is necessary for network stability and edge detection. This cloning template describes the strength of the nearest-neighbor interconnections in the network. The proposed approach with the cloning template given in Eq. (11) is applied on the anomaly map of model 1, and CNN output is demonstrated in Fig. 4(c). CNN can be seen here to delineate the edges of the prisms quite well. To compare the proposed approach with classical derivative techniques, the CC method is applied onto the same gravity anomaly map. This method is based on CC between the synthetic anomaly due to a vertical step and the second vertical derivative of the gravity anomaly. The CC for a finite length of the second vertical derivative of the synthetic anomaly due to a step $g_{t}^{\prime \prime}\left(x^{\prime}\right),\left(x^{\prime}=-n, \ldots, 0, \ldots, n\right)$, and the second vertical derivative of the observed anomaly $g_{o}^{\prime \prime}\left(x^{\prime}\right),(x=1,2, \ldots, m)$, can be expressed as

$$
r_{g_{o}^{\prime \prime} g_{t}^{\prime \prime}}(x)=\sum_{x^{\prime}=-n}^{n} g_{o}^{\prime \prime}\left(x^{\prime}+x\right) g_{t}^{\prime \prime}\left(x^{\prime}\right)
$$

where $x=n+1, n+2, \ldots, m-n$ and $n<m$.

The CC maps in the E-W and N-S directions are obtained by Eq. (12) as shown in Figs. 4(d), (e). The edges of the prisms are located from the closed maxima or minima on these maps calculated for two perpendicular directions. Since some small closed extrema may be produced by highfrequency noise in the second vertical derivative map, only the closed extrema with a clear elongation direction are chosen. Although the outputs derived from the $\mathrm{CC}$ analysis are somewhat noisy (Figs. 4(d), (e)), the CNN method yields quite distinct prism borders (Fig. 4(c)).

The edges of the prisms are determined using the standard Canny algorithm (Fig. 4(f)) as well. The results of the Canny and CNN algorithms are similar in the case of simple models.

In summary, it can be stated that $\mathrm{CNN}$ is the more powerful tool for detecting the border of a vertical prism.

\subsection{Multiple sources (model 2)}

To determine geologic boundaries, a more sophisticated model, shown in Fig. 5(a), is used. A new synthetic model is formed by using vertical blocks that are located at various depths. The model is $61 \times 61$ pixels wide; the synthetic gravity anomaly map of this model is shown in Fig. 5(b). The same procedure used for model 1 was repeated to locate the edges of causative sources. Figure 5(c) shows the edges map obtained by CNN method: the N-S trending lineaments are quite distinct at the $\mathrm{CNN}$ output. To compare CNN with classical derivative methods, the $\mathrm{CC}$ technique was also tested on the same data. Geologic boundaries are located from the closed maxima or minima on the CC contour maps calculated in the E-W and N-S directions (Figs. 5(d) and 5(e), respectively). The CC technique produced false edges that are not present in the input map. The 

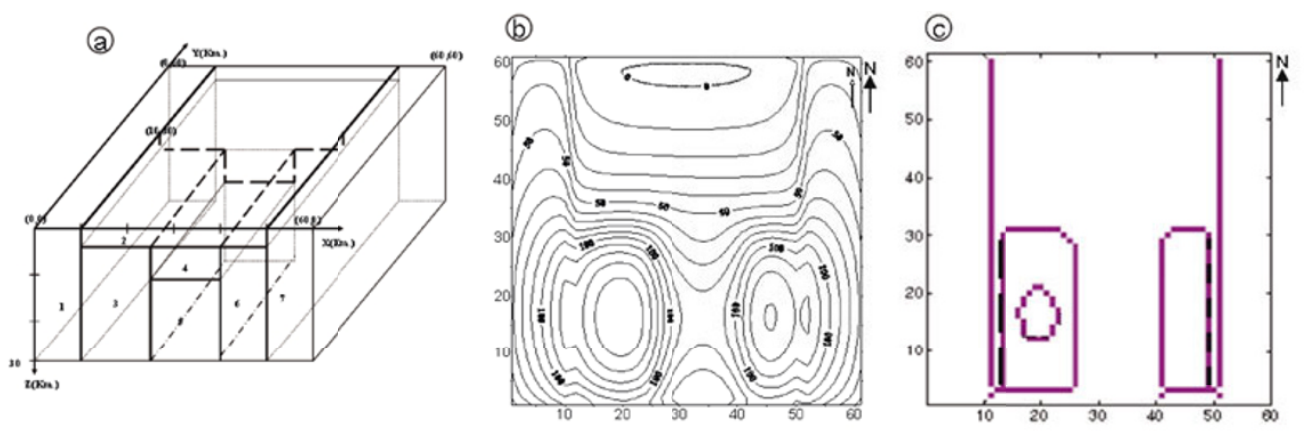

(d)

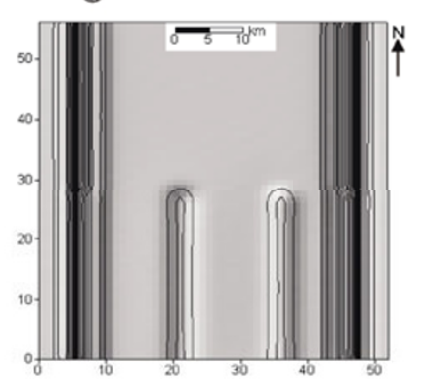

(e)

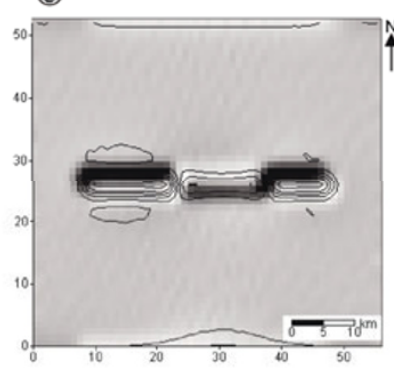

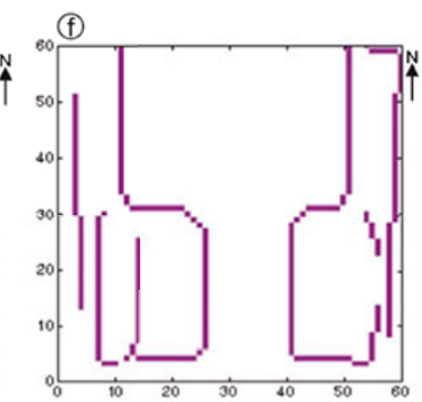

Fig. 5. Synthetic example: (a) Schematic outlines of model 2, (b) synthetic anomaly map (contour interval is $10 \mathrm{mGal}$ ), (c) edge map obtained from $\mathrm{CNN}$, (d) gray-shaded relief of cross-correlation map in the E-W direction, (e) gray-shaded relief of cross-correlation map in the N-S direction, (f) edge map obtained by standard Canny algorithm. Cross-correlation maps are illuminated from the NW.

edges of the prisms are also determined using the standard Canny algorithm (Fig. 5(f)).

In this example, the border of prism 5 overlain by the prisms 2 and 4 are excellently determined by CNN. However, the results are not satisfactory for the locations of the edges of the prisms 3 and 6 (indicated with dashed lines in Fig. 5(c)). This drawback of CNN can be overcome by more detailed training on complex models. Similar results are observed in the CC outputs (Fig. 5(d)), although the N$\mathrm{S}$ elongated edges are located successfully (Figs. 5(c), (e)). Figure 5(f) shows that the Canny method fails to detect borders in complex structures. These results show that the proposed CNN algorithm produced fairly good results on both the simple and more complex synthetic examples.

The performance of CNN is quite good. The feedback and control template play an important role in the CNN. In terms of the estimation power and the computation time, $\mathrm{CNN}$ can be considered to be an effective and powerful tool in solving geophysical problems.

\section{Geological Features of the Southern Marmara Region}

In the southern Marmara region, the development of Neogene-Quaternary tectonostratigraphic units is controlled mainly by the branches of the North Anatolian Fault (NAF). The NAF is a major, active right-lateral strike-slip fault (Ketin, 1969; Jackson and McKenzie, 1988; Barka, 1992; Fig. 6) that constitutes the northern boundary of the westward-moving Anatolian Block and connects the compressional regime in eastern Anatolia with the extensional regime in the Aegean Sea region (McKenzie, 1972; Şengör, 1979; Dewey et al., 1986). The NAF extends from the Karliova triple junction, where it meets the sinistral East

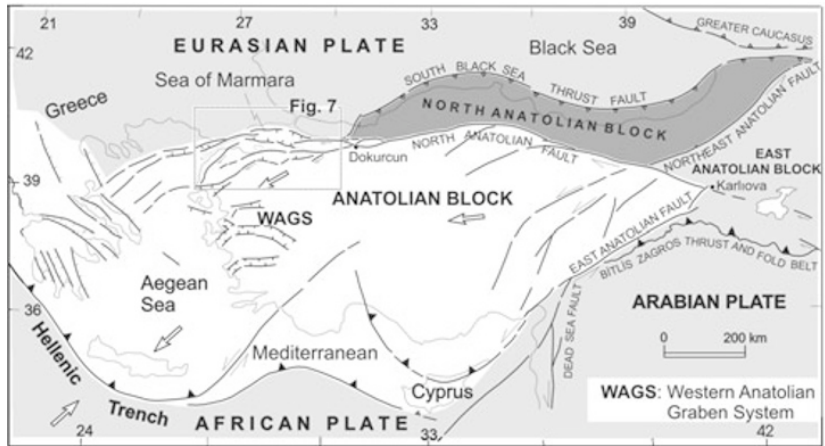

Fig. 6. Simplified tectonic map of the Anatolian region and surroundings showing the main tectonic domains developed during Miocene to Holocene time (from Elmas, 2003 and modified from Letouzey et al., 1977; Şengör et al., 1985; Barka and Kadinsky-Cade, 1988; Jackson and McKenzie, 1988).

Anatolian Fault, to the North Aegean region (Dewey and Şengör, 1979). To the west of Dokurcun (Fig. 6), the NAF zone splits into two branches. In the Marmara region (Fig. 7), these two branches are divided into subbranches: the northern, middle and southern branches. Towards the south of the Marmara Sea, the middle and southern branches become shorter and discontinuous and create many basins, such as the İznik, Bursa, Karacabey, Manyas, Nilüfer-Karacabey (Barka and Kadinsk-Cade, 1988; Gürer et al., 2003) and Northern Sakarya Low (Elmas, 2003).

There are two main rock groups in the study area: the Pre-Neogene basement and the Neogene-Quaternary cover (Fig. 8). The Pre-Neogene basement comprises Triassicaged metamorphic association (Karakaya complex; Bingöl et al., 1973), Mesozoic-aged carbonates, Palaeogene-aged granitoids and Eocene volcaniclastics (Altınlı, 1973). The 


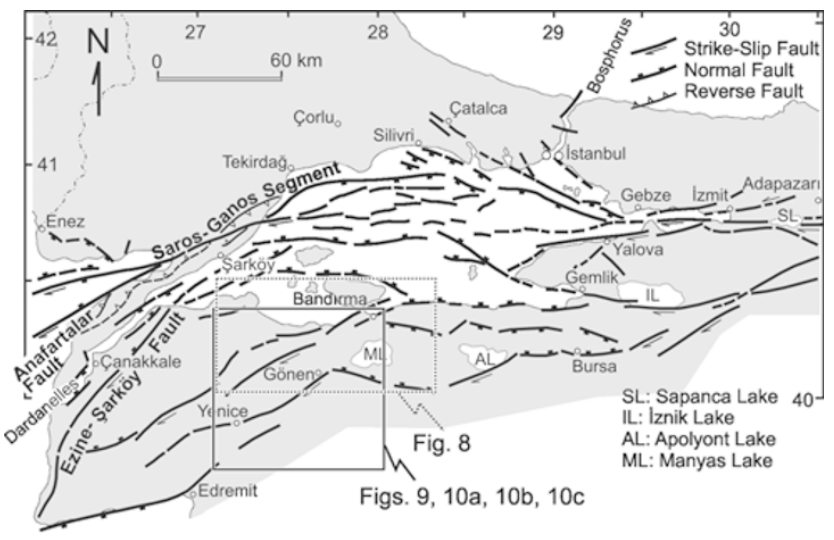

Fig. 7. Tectonic map of northwestern Turkey, showing faults developed during Miocene to Holocene times. Data for the area around the Dardanelles are from Elmas and Meriç (1998), the southern, eastern and northeastern Marmara regions from Elmas (2003) and the Sea of Marmara compiled from data by Smith et al. (1995), Okay et al. (1999), İmren et al. (2001) and the Turkish Petroleum Company (unpublished data).

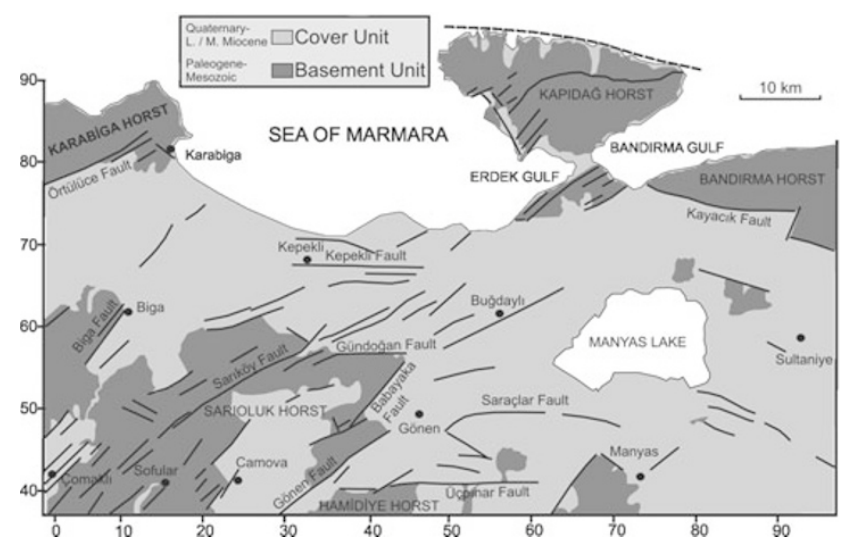

Fig. 8. Geological map of southwest Marmara region (simplified from Gürer et al., 2006).

Neogene-Quaternary cover unit consists of fluvial, alluvial, deltaic, lacustrine sedimentary deposits and volcanic rocks (Emre et al., 1997; Sahbaz et al., 1998; Gürer et al., 2006).

Many of the faults and horsts in the study area between Bandırma, Manyas, Yenice and Biga have been mapped in detail and subsequently named by Gürer et al. (2006). The most prominent morphological entities are the Kapıdağ, Karabiga, Sarıoluk, Hamidiye and Bandırma horsts (Fig. 8). Gürer et al. (2006) recognize two first-order faults: one suite of faults trends approximately E-W, parallel to the Marmara margin faults and dominates the east of the study area; the second group of faults trends NE-SW and dominates the west of the area (Fig. 8). These two sets of faults controlled the development of the Plio-Quaternary deposits (Gürer et al., 2006).

\section{Application to Real Data}

A simplified gravity anomaly map showing the major structural features of Biga and surrounding area (obtained from General Directorate of Mineral Research \& Exploration (MTA)) is shown in Fig. 9. The region was chosen because detailed geophysical exploration studies identified

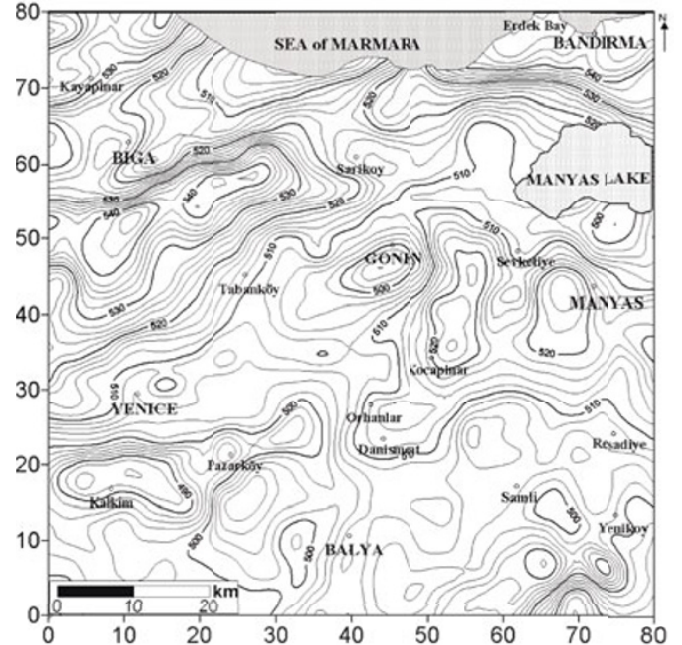

Fig. 9. Bouguer anomaly map of Biga and surrounding areas (obtained from MTA). Contour interval is $2 \mathrm{mGal}$.

several NE-SW-trending faults traces as prominent features. The Bouguer anomaly map was digitized at $1-\mathrm{km}$ intervals, resulting in a data matrix of $81 \times 81$; this data matrix was used as the input data to $\mathrm{CNN}$ algorithm to determine geologic boundaries in the region.

Here we choose CNN technique for determining the geologic boundaries by virtual of the fact that it has various filtering characteristics owing to the cloning template. It is also widely used for residual-regional separation as well as border detection by choosing an appropriate cloning template. In this example, the Bouguer anomaly values of Biga and the surrounding areas are used in the CNN as input data, and the cloning template in Eq. (11) is used to detect geologic boundaries that are difficult to identify in the Bouguer anomaly map. CNN output is shown in Fig. 10(a). This map clearly shows that both major faults having large vertical displacements and minor faults that are not obvious in the Bouguer anomaly map are well defined using the CNN approach. The WNW-ESE trending strong gravity gradient to the north of Manyas Lake (Fig. 9), extending also beneath the lake, shed light on a likely normal fault dipping SSW. Although the normal fault is not present on the active faults map of Turkey (Şaroğlu et al., 1992), there are several pieces of evidence supporting the existence of such a normal fault: (1) the regional stress tensor analysis based on focal mechanisms of earthquakes in the Marmara sea region indicate a NW-SE directed (1-axis and NE-SW trending $\sigma 3$-axis (Pinar et al., 2003) where one may expect a SSW-dipping normal fault; (2) the location and the predominantly normal faulting mechanism with WNW-ESEtrending nodal planes of the 1964 Manyas-Karacabey earthquake $(\mathrm{Mw}=6.6)$ suggest the existence of this normal fault (Eyidoğan, 1991).

To compare the $\mathrm{CNN}$ method with classical derivative techniques, the $\mathrm{CC}$ method is also applied on the same Bouguer anomaly map. The maxima or minima in the CC maps in the E-W and N-S directions (Figs. 10(b) and (c), respectively) as derived from the $\mathrm{CC}$ technique enable geologic boundaries of causative sources to be detected. 

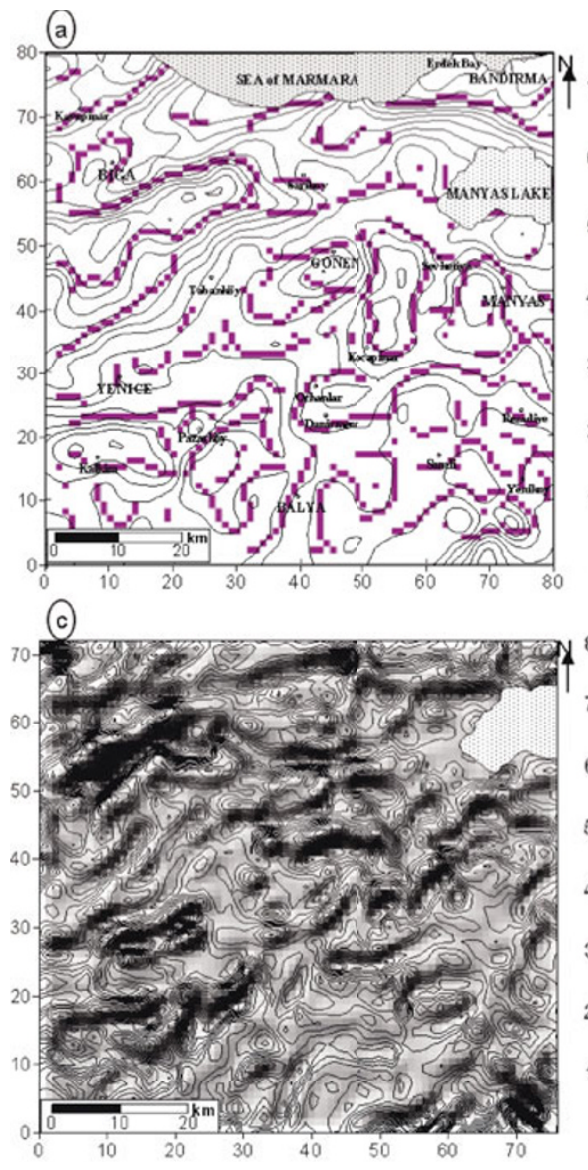

(b)

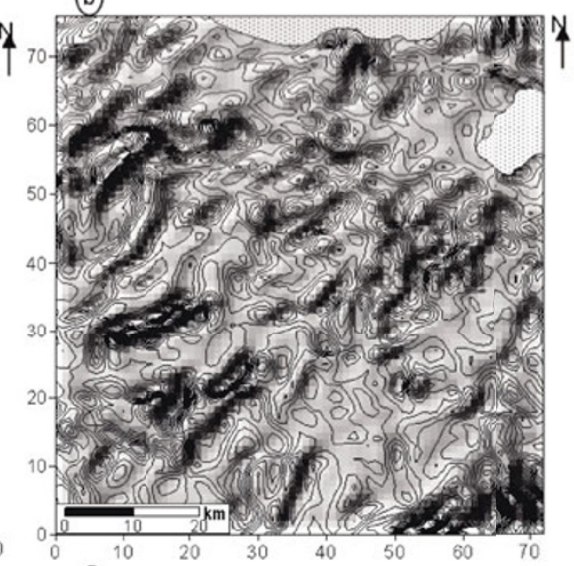

(d)

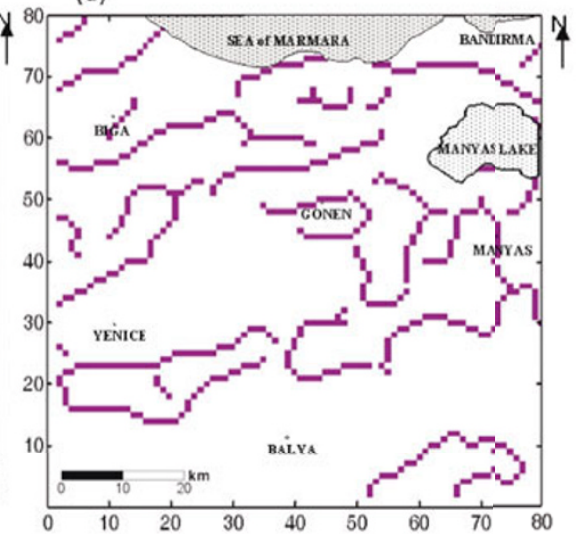

Fig. 10. (a) Edge maps obtained by proposed approach, (b) gray-shaded relief of cross-correlation map in the E-W direction, (c) gray-shaded relief of cross-correlation map in the N-S direction, (d) edge map obtained by standard Canny algorithm. Cross-correlation maps are illuminated from the NW.

Figure 10(a)-(c) shows that the CNN and CC methods are similar in terms of their performance to detect major faults and minor faults. Thus, it can be concluded that the CNN is an effective method for detecting geologic boundaries, such as faults or the boundary of two geologic zones.

The CNN and the CC outputs shown in Fig. 10(a)(c), which were obtained from the Bouguer anomaly map (Fig. 9), show that the position of faults generally correlate well with those of geological map of the region (Fig. 8). Many of the E-W- and NE-SW-trending faults in previously published geological maps (Elmas and Meriç, 1998; Elmas, 2003; Smith et al., 1995; Okay et al., 1999; İmren et al., 2001; Gürer et al., 2006; Figs. 7 and 8) are obvious in the CNN and CC outputs (Figs. 10(a)-(c)). On the other hand, the strike-slip fault that was ruptured by the 1953 YeniceGönen earthquake (Figs. 7 and 8) was not detected in the $\mathrm{CNN}$ and $\mathrm{CC}$ outputs even though it is present in the geological maps. We believe that this fault is not revealed in the processed data either because of insufficient and/or sparse data collection in the field or because the gravity data are not sensitive to lateral motions.

\section{Discussion and Conclusions}

In this paper, an image processing technique called CNN approach is introduced as an approach for locating subsurface geological features such as faults or the boundary of two geologic zones. $\mathrm{CNN}$ is a stochastic image processing technique based on template optimization using the neighborhood relationships of cells. The network dynamic of a $\mathrm{CNN}$ is described by a set of differential equations. Each cell in a CNN has an input, an internal state and an output. The feedback control template represents the coupling coefficients of the cells, and this completely defines the behavior of the network with a given input and initial condition.

$\mathrm{CNN}$ is first applied on two synthetic data sets to detect the borders of vertical prismatic blocks, and the results are compared with those obtained with the $\mathrm{CC}$ technique. After satisfactory results had been verified, the proposed CNN algorithm is applied on the gravity anomaly map of Biga and surrounding area in Anotalia to evaluate the major and minor faults. The structural features in the area between Bandirma, Biga, Yenice and Gonen in the southwestern Marmara region are investigated by applying the $\mathrm{CNN}$ and $\mathrm{CC}$ algorithms to the Bouguer anomaly map. As shown in Fig. 10(a), the CNN output provides a better visualization of the outlines of the geologic features. The results of the proposed approach (Fig. 10(a)) are in good agreement with previously observed faults in the field (Elmas and Meriç, 1998; Elmas, 2003; Smith et al., 1995; Okay et al., 1999; Imren et al., 2001; Gürer et al., 2006; Figs. 7 and 8). It is shown that the CNN and CC methods are similar in terms of their performance in detecting geologic boundaries.

The proposed tectonic map (Fig. 10(a)) of the area between Bandirma, Biga, Yenice and Gonen in the south- 
western Marmara area, which was prepared by applying the CNN method to the gravity anomaly map, reveals the existence of two distinct groups of faults: one suite of faults has approximately WNW-ESE trends and dominates in the east and south of study area; the second group of faults trends NE-SW and dominates in the west of the area (Fig. 10(a)). It would seem that the structural results and the tectonic map of the region, the latter of which was prepared by applying the CNN method to the gravity anomaly map, are predominantly in accordance with the results of previous field studies. Moreover, the use of this method provides a more detailed general view of structural features. For example, the strongly gravity anomaly to the north of Manyas Lake (Fig. 9) indicates the existence of a fault which displays a progressive change in trend from NW in the east to $\mathrm{E}-\mathrm{W}$ in the west. The fault has not been identified by previous field studies.

Consequently, by applying the proposed approach to the Bouguer anomaly map, a detailed general view of surface and subsurface structural boundaries can be obtained successfully. The CNN method, as applied to the location of edges of causative sources, is simple and easy to use and is a good approach for determining vertical or near vertical faults. Thus, this method can be a useful geophysics tool for investigating structural boundaries over wide areas.

Acknowledgments. I would like to express my thanks to Dr. Takeshi Sagiya (Editor and reviewer) and Dr. Masao Komazawa (reviewer) for their very careful reading, valuable comments, modifications and suggestions. I thank Dr. Ali Elmas, Dr. Ali Pınar and Dr. Aysan Gürer for their very careful reading and suggestions on the text.

\section{References}

Altınlı, İ. E., The geology of middle Sakarya, Congress Proceeding of Earth Sciences 50th Anniversary of Turkish Republic. Min. Res. and Exp. Inst. (M.T.A), Ankara, 159-191, 1973 (in Turkish).

Aydogan, D., A. Elmas, A. M. Albora, and O. N. Ucan, A new approach to the structural features of the Aegean Sea: Cellular neural network, Mar. Geophys. Res., 26, 1-15, 2005.

Barka, A. A., The North Anatolian fault zone, Annales Tectonicae, 6, 164 195, 1992.

Barka, A. A. and K. Kadinsky-Cade, Strike-slip fault geometry in Turkey and its influence on earthquake activity, Tectonics, 7, 663-684, 1988.

Bingöl, E., B. Akyürek, and B. Korkmazer, The geology of Biga Peninsula and the features of Karakaya Formation, Congress Proc of Earth Sci 50th Anniversary of Turkish Republic: Min. Res. and Explor. Inst., Ankara, 70-77, 1973 (in Turkish).

Blakely, R. J. and R. W. Simpson, Approximating edges of source bodies from magnetic or gravity anomalies, Geophysics, 51(7), 1494-1498, 1986.

Boschetti, F., Improved edge detection and noise removal in gravity maps via the use of gravity gradients, J. Appl. Geophys., 57, 213-225, 2005.

Canny, J., A computational approach to edge detection, IEEE Transaction on Pattern Analysis and Machine Intelligence PAMI, 8(6), 679-698, 1986.

Chua, L. O. and L. Yang, Cellular neural networks: Theory, IEEE Transaction on Circuits and Systems, 35(10), 1257-1272, 1988a.

Chua, L. O. and L. Yang, Cellular neural networks: Applications, IEEE Transaction on Circuits and Systems, 35(10), 1273-1290, 1988b.

Dewey, J. F., M. Hempton, W. Kidd, F. Şaroğlu, and A. M. C. Şengör, Shortening of continental lithosphere: the neotectonics of eastern Anatolia: a young collision zone, in Collision tectonics, edited by M. P. Coward and A. C. Ries, Geol. Soc. Lond. Spec. Publ., 19, 3-36, 1986.

Dewey, J. F. and A. M. C. Şengör, Aegean and surrounding regions: complexmultiplate and continuum tectonics inaconvergent zone, Geol. Soc. Am. Bull., 90, 84-92, 1979.
Elmas, A., Late Cenozoic tectonics and stratigraphy of Northwestern Anatolia: the effects of the North Anatolian Fault to the region, J. Int. Earth Sci., 92, 380-396, 2003.

Elmas, A. and E. Meriç, The seaway connection between the Sea of Marmara and the Mediterranean: tectonic development of the Dardanelles, Int. Geol. Rev., 40, 144-162, 1998.

Emre, Ö., T. Erkal, N. Kazanc1, İ. Kuşcu, and M. Keçer, Morphotectonics of the southern Marmara region during the Neogene and Quaternary, Görür, N. (ed.), Kuzey Ege, Marmara Denizi ve dolayının jeolojisi deniz yapılaşmalarındaki önemi Kolokyumu. İTÜ Extended abstracts 7-17, 1997.

Eyidoğan, H., Z. Utku, U. Güçlü, and E. Değirmenci, The macroseismic guidance of the large Turkish earthquakes (1900-1988), ITU, Istanbul, 1991.

Fedi, M. and G. Florio, Detection of potential fields source boundaries by enhanced horizontal derivative method, Geophys. Prospect., 49, 40-58, 2001.

Gürer, Ö. F., N. Kaymakçı, Ş. Çakır, and M. Özburan, Neotectonics of the southeast Marmara region, NW Anatolia, Turkey, J. Asian Earth Sci., 21, 1041-1051, 2003.

Gürer, Ö. F., E. Sangu, and M. Özburan, Neotectonics of the SW Marmara region, NW Anatolia, Turkey, Geol. Mag., 143(2), 1-13, 2006.

İmren, C., X. Le Pichon, C. Rangin, E. Demirbağ, B. Ecevitoğlu, and N. Görür, The North Anatolian Fault within the Sea of Marmara, A new interpretation based on multi-channel seismic and multi-beam bathymetry data, Earth Planet. Sci. Lett., 186, 143-158, 2001.

Jackson, J. and D. P. McKenzie, The relationship between plate motions and seismic moment tensors and the rates of active deformation in the Mediterranean and Middle East, Geophys. J., 93, 45-73, 1988.

Ketin, İ., About of the North Anatolian Fault, Bull. Min. Res. Expl. Inst., Turkey, 72, 1-25, 1969.

Letouzey, J., B. Biju-Duval, A. Dorkel, R. Gonnard, K. Kristchev, L. Montadert, and O. Sungurlu, The Black Sea: a marginal basin, Geophysical and geological data, in International Symposium on the Structural History of the Mediterranean Basins, edited by B. Biju-Duval and L. Montadert, 363-376, 1977, Editions Technip (Paris).

McKenzie, D. P., Active tectonics of the Mediterranean region, Geophys. JR. Astron. Soc., 30, 109-185, 1972.

Okay, A. I., E. Demirbağ, H. Kurt, N. Okay, and İ. Kuşçu, An active, deep marine strike-slip basin along the North Anatolian Fault in Turkey, Tectonics, 18, 129-147, 1999.

Pınar, A., Y. Honkura, and K. Kuge, Moment tensor inversion of recent small to moderate sized earthquakes: Implication for seismic hazard and active tectonics beneath the Sea of Marmara, Geophys. J. Int., 152, 133145, 2003.

Reid, A. B., J. M. Allsop, H. Granser, A. J. Millett, and I. W. Somerton, Magnetic interpretation in three dimensions using Euler deconvolution, Geophysics, 55, 80-91, 1990.

Sahbaz, A., M. Özdoğan, S. Görmüş, and E. Bayhan, Sedimentology of Mudanya formation: depositional processes controlling the development of Gilbert type fan delta (Middle-Late Miocene, South of Marmara Sea), Yerbilimleri, 20, 111-122, 1998.

Smith, A. D., T. Taymaz, F. Oktay, H. Yüce, B. Alpar, H. Başaran, A. J. Jackson, S. Kara, and M. Şimşek, High-resolution seismic profiling in the Sea of Marmara: Late Quaternary sedimentation and sea-level changes, Geol. Soc. Am. Bull., 107, 923-936, 1995.

Sykes, M. P. and U. C. Das, Directional filtering for linear feature enhancement in geophysical maps, Geophysics, 65, 1758-1768, 2000.

Şaroğlu, F., Ö. Emre, and İ. Kuşu, Active fault map of Turkey, MTA, 1992.

Şengör, A. M. C., The North Anatolian transform fault: its age, offset and tectonic significance, J. Geol. Soc. Lond., 136, 269-282, 1979.

Şengör, A. M. C., N. Görür, and F. Şaroğlu, Strike-slip faulting and related basin formation in zones of tectonic escape: Turkey as a case study, in Strike-slip Basin Formation and Sedimentation, edited by K. T. Biddle and N. Christie-Blick, Soc. Econ. Paleon. Min. Spec. Publ., 37, 227264, 1985.

Thompson, D. T., EULDPH: A new technique for making computerassisted depth estimates from magnetic data, Geophysics, 47, 31-37, 1982.

Zeng, H., Q. Zhang, and J. Liu, Location of secondary faults from crosscorrelation of the second vertical derivative of gravity anomalies, Geophys. Prospect., 42, 841-854, 1994.

D. Aydogan (e-mail: aydogan@istanbul.edu.tr) 